\title{
Presentación del dossier: Artes escénicas y traducciones
}

\author{
(1) Micaela van Muylem \\ Facultad de Lenguas, Universidad Nacional de Córdoba, Argentina \\ micaela.van@unc.edu.ar

\section{Laura Fobbio} \\ Facultad de Filosofía y Humanidades, Universidad Nacional de Córdoba / Facultad de Arte y \\ Diseño, Universidad Provincial de Córdoba, Argentina \\ laurafobbio@unc.edu.ar
}

Fecha de recepción: 21/4/2021. Fecha de aceptación: 28/05/2021

\begin{abstract}
Uma parte de $\mathrm{mim} /$ é todo mundo; / outra parte é ninguém;/ fundo sem fundo./ Uma parte de mim/ é multidāo;/ outra parte estranheza/e solidāo/ (...) Uma parte de mim/é só vertigem/ outra parte,/linguagem./ Traduzir uma parte/ na outra parte/ - que é uma questāo/ de vida ou morte—/ será arte?

(Ferreira Gullar, “Traduzir-se”)
\end{abstract}

El eje que convoca y atraviesa el presente Dossier, Artes escénicas y traducciones, interpela el trabajo que realizamos en los últimos años en el marco de investigaciones sobre teatro argentino y europeo. En una primera instancia, la traducción funcionó como herramienta para acercarnos a obras escritas en otras lenguas, sobre todo, en alemán y neerlandés. En el contexto de esas investigaciones, se gestó en 2012 la Colección Papeles Teatrales (Editorial de la Facultad de Filosofía y Humanidades, Universidad Nacional de Córdoba, con dirección de Adriana Musitano), espacio que entrama investigación escénica, traducción, poesía, plástica y edición de libros de/ sobre dramaturgias, prácticas que concebimos como liminales ${ }^{1}$. En ese proyecto advertimos la necesidad de reflexionar sobre las traducciones de la escena al papel, lo que dio lugar a conceptos como el de "puesta en página" (Musitano y Fobbio, 2012; Fobbio y van Muylem, 2020a y 2020b). La traducción fue cobrando, entonces, protagonismo por su funcionalidad teórico-metodológica, y nos permitió definir nuestra práctica investigativa al abordar y distinguir poéticas dramatúrgicas que se valen de 
esa operación como procedimiento de pasaje, apropiación en las diferentes instancias del proceso creativo (mise en abyme de discursividades, corporalidades y experiencias), y como práctica artística en sí misma:

Trasponer, adaptar, parafrasear, comentar, parodiar, recodificar, remitir, reescribir, trasladar, transformar, apropiar, citar, mediar, vulgarizar, traicionar, teorizar, interpretar, explicar... ¿ ¿todo es traducir? En parte sí, porque la traducción es mucho más que una mera transposición lingüística que hace pasar un texto de una lengua a otra; es, fundamentalmente, una operación intercultural en la que se adaptan sistemas sígnicos diferentes (...) y es, también, un permanente conflicto entre el deseo de totalidad, de perfección y la aceptación de su imposibilidad (Trastoy, 2012: 245-246).

En las dramaturgias de postvanguardia, lo autorreferencial como procedimiento recurrente es reformulado y expande el concepto de traducción, como una "forma de reflexionar sobre lo propio y sobre lo ajeno, un intento de comprendernos y de comprender a los otros" (Trastoy, 2017: 183). Así, los cruces entre lo individual y lo colectivo que caracterizan a las traducciones en la escena autorreferencial del siglo XXI, nos llevan a actualizar la mirada en este contexto pandémico en el que -apropiándonos del epígrafe de Ferreira Gullar arriba citado-, una parte de nosotros es "multitud" y, otra parte, "extrañeza y soledad". Preguntarse por las interacciones entre artes escénicas y traducciones en este panorama que atomiza las bases epistemológicas desde las que veníamos pensando la escena, que nos despalabra, plantea suspensos, distancia, reafirma inequidades y violencias, y nos expone ante la muerte, comporta un desafío otro para nosotras y para les autores: revisar lecturas y recorridos, mirar-se desde la incertidumbre, (re)traducir-se en un diálogo necesario con la comunidad.

Para conformar el presente Dossier invitamos a especialistas que se destacan en diferentes espacios de investigación en y para la escena, como son la creación, la docencia, la edición y la traducción. Al recibir los textos, observamos una apropiación singular de nuestra propuesta, ya que cada une reflexionó desde su hacer en relación con las artes escénicas, y propuso interrogantes y perspectivas que aportan a la diversidad de concepciones sobre la traducción, lo que nos llevó a plantear tres momentos en la composición del Dossier. En Traducir las experiencias, dialogan los textos de Laurent Berger y Juan Miranda sobre las vivencias de les artistas cuando se traduce en/para la escena; en Traducirlas miradas, Catalina Cepernic, Lucas Margarit y Adriana Musitano comparten inquietudes al analizar dramaturgias que sientan precedentes en las artes escénicas de postvanguardia; y en Traducir la traducción, Cepernic presenta la primera traducción al español de "El texto como objeto. Sobre la autonomía recuperada del texto dramático" de Ronald Geerts. Les autores problematizan la traducción al tiempo que la emplean como herramienta, y así los textos transitan por fragmentos de obras, notas, citas teóricas y entrevistas en diferentes lenguas (español, francés, inglés, italiano, neerlandés) traducidos para este volumen.

TRADUCIR LAS EXPERIENCIAS. En "El idioma del actor y la traducción infinita", Laurent Berger, situado en su multidisciplinar vinculación con la escena como director, dramaturgista, investigador y profesor, atomiza el concepto de traducción desde la producción misma de este texto que escribe primero en francés -su "lengua materna"-y luego traslada al español. Berger recorre las distintas modalidades que cruzan artes escénicas y traducción a lo largo del proceso creativo, haciendo foco en el trabajo lingüístico, el pasaje del texto dramático a la escena y las múltiples lecturas que atraviesan a la obra a lo largo de la historia de la cultura en lo que denomina "visión latente": "ese limbo de interpretaciones, imágenes y asociaciones que envuelve la obra original, pero expande considerablemente su dominio". Hace zoom en la poética de Shakespeare y sus resonancias, tema sobre el que investigó en profundidad 
fuera y dentro de la escena, y que tradujo como director de la puesta $38 \mathrm{SM}$ (Shakespeare Material), estrenada en el Teatro Nacional Argentino-Teatro Cervantes en 2017. Reflexiona sobre la operación de traducción entendida como "movimiento amplio de mutación", "destrucción programada", "empresa imposible", "objeto" y "objetivo". Asimismo, desde la perspectiva del autor, las dinámicas que implica la traducción concebida en una "dimensión cumulativa y asociativa" -en tanto "etapa del proceso de transformación e interpretación de la obra"-, permite entender dicho proceso y "describir algunos matices del trabajo del actor". Berger se detiene en ese punto para reflexionar sobre el sentido colectivo de lo que denomina "traducción total", que se produce en la interacción entre les artistas, destacando la "visión expansiva" del director y el idioma "interior" e "indescifrable" del actxr en el que confluyen sensibilidad, experiencia, carnadura. Berger reconoce la "energía excéntrica" de la traducción, es decir, "el uso de las múltiples variantes que generan las diferentes traducciones posibles", para pensar en la posibilidad de que se monten en escena, al mismo tiempo, varias versiones de un texto, posicionamiento que lleva a relativizar la pérdida asociada al paso del idioma original al idioma meta, en un fenómeno de retraducción y "circulación continua".

Juan Miranda presenta "Noli me tangere, todavía no soy una imagen", texto en el que recorre lecturas y decisiones que atravesaron el proceso creativo de Pathos, investigación escénica que dirigió e interpretó en el marco del Máster Das Theatre en la Universidad de las Artes de Ámsterdam, y en la que tradujo sus indagaciones como actor, director, dramaturgo y docente. Miranda parte de las palabras que Jesús dice a María Magdalena después de la resurrección y de la pintura de Fra Angelico (Noli me tangere), para reflexionar sobre imagen y escena, situado en el entre cuerpos; en la tensión entre presencia y ausencia; escena e imaginación; teatro, artes visuales y performance; pathos e imagen; ficción y realidad; arte y vida. Desde allí problematiza, en este contexto de distanciamiento social y crisis sanitaria global: “¿Qué significa tocar y ser tocado? ¿Cómo nos mueve y conmueve una imagen? ¿Cuál es la necesidad de sentir emociones no sólo colectivamente, sino también compartiendo el mismo espacio físico?". Esas preguntas se encabalgan a otras, y en la búsqueda de respuestas, el autor define la imagen y desanda la traducción de Noli me tangere al dispositivo escénico que diseña en Pathos donde, según describe, "la circulación del público es una coreografía en sí misma que extiende y configura la propuesta". En la traducción de la experiencia que trazan sus apuntes y notas -como decide nombrarlos-, Miranda se detiene a clasificar lo que denomina "tres posibilidades o categorías" del pathos: "soy ante mí mi propio teatro", retomando a Barthes; "ni cuerpo animal, ni humano: pura carne", y "puro estado de alerta y escucha". Luego de la lectura del texto quedan resonando afirmaciones como la siguiente: "no existe confinamiento posible que aísle a la pregunta artística de su entorno, ya que es imposible pensar un proceso creativo des-aprehendido de su tiempo".

TRADUCIR LAS MIRADAS. Catalina Cepernic es investigadora, traductora y docente de neerlandés y en su artículo "El texto en escena: operaciones en la puesta de GAS/ GAZ de Tom Lanoye", aborda el monólogo (¿y nouvelle?) del dramaturgo, poeta y novelista belga Tom Lanoye, que fue llevado a escena en Chile y Argentina por la compañía teatral Magdalena en 2017. En una obra en la que, desde Europa, se reflexiona sobre historia y política, se encuentran pasado y presente, experiencias colectivas e individuales, Cepernic examina los diferentes cruces, tensiones y traducciones entre lenguas y lenguajes artísticos de esa puesta que resignifica la propuesta flamenca. La autora analiza de qué manera la obra, escrita en neerlandés y traducida al castellano rioplatense, es llevada a escena en un español chileno con acento alemán. La lengua es así una protagonista que, a su vez, se materializa como objeto, en el papel del cual lee la actriz Heidrun Breier tanto didascalias como su parlamento, y el texto "se configura como objeto de exposición", "a la vez que el lenguaje se vuelve un objeto 
tangible en escena, el texto dramático pierde su autoridad y se vuelve un elemento que puede ser modificado, fusionado, eliminado, expuesto". Cepernic logra establecer vínculos entre los diferentes lenguajes y disciplinas y piensa, desde las propuestas de Geerts y Garramuño, cómo esta obra pone en diálogo problemáticas y búsquedas latinoamericanas y europeas, y de qué manera se plantean nuevas formas de habitar el mundo desde lo inespecífico y la diferencia.

Lucas Margarit, investigador, docente, poeta y traductor, especialista en Samuel Beckett, William Shakespeare, poesía isabelina y la poesía inglesa del siglo XX, en "Traducción y traslado: aquellas otras palabras en el teatro de Stoppard" propone observar de qué manera confluyen la traducción y la (im)posibilidad de traducción en Dogg's Hamlet, Cahoot's Macbeth de Stoppard. En estas dos piezas se alternan tanto (re)traducciones como la ausencia de la traducción, y surge así un "hiato entre la acción, la palabra y el espectador". Si a Stoppard siempre le interesó la reescritura (que es una manera de traducir una obra de otro tiempo y espacio), en estas piezas basadas en las tragedias de Shakespeare explora el proceso de aprendizaje de ciertas reglas de los "juegos de lenguaje" de Wittgenstein con las cuales se ven confrontades tanto actores y actrices en escena como así también el público, dado que todes deben aprender y desaprender su propia lengua (y/o "el idioma dogg"), que constantemente parece devenir otra. Margarit presenta, a partir de una serie de situaciones, en traducciones propias de diálogos que desafían toda lógica, ejemplos concretos sobre este cuestionamiento de la posibilidad de comprender e interpretar aquello que vemos y oímos en la escena y en la realidad: sostiene que quizá "todo acto de interpretación no es más que una continua traducción parcial de aquello que logramos ver y escuchar sobre un escenario", y/o en relación con les otres.

En "Ethica. Natura e origine della mente: una performance que suspende y triangula luz/ cuerpo/mente", Adriana Musitano, investigadora, poeta, docente y editora, reflexiona sobre esa performance concebida por Claudia y Romeo Castellucci. Especialista en teatro de postvanguardia y, en particular, en la poética de les Castellucci, la autora realiza una operación de traducción analítica donde la figura del triángulo le permite tensionar luz/cuerpo/mente para repensar esa puesta -que vio en 2019 en el Teatro Coliseo de Buenos Aires en el marco de la Bienal de Performance-, desde una revisión crítico-reflexiva atravesada por el contexto pandémico. Es decir que el punto de partida y al que siempre vuelve es Ethica. Natura e origine della mente, pero desde lecturas que se diversifican y plantean un recorrido sugerente que traslada a les lectores por recuerdos y registros de la performance; textos metapoéticos; traducciones del italiano; lecturas de/sobre Spinoza; reflexiones de García Canclini, Jameson, Steiner; poesía; La invención de Morel de Bioy Casares; imágenes plásticas; entre otros. Con la certeza de que "Todo/nada puede ser traducido", Musitano traduce su experiencia de espectadora-investigadora y desde allí nos interpela: “¿cómo pensamos/percibimos/ experimentamos para la felicidad? ¿Cómo definimos/conocemos nuestra Mente/Cuerpo? ¿Qué efectos imaginarios/racionales producen la presencia/puesta en escena no representacional?". Ensaya respuestas que abren nuevos interrogantes, al desafiarnos respecto de las tensiones entre lo geométrico, lo poético y lo ético; el reconocimiento de distorsiones y quiebre de los significantes; la alegoría como enigma; la suspensión como procedimiento en la puesta y como concepto para pensar nuestra actualidad; Ethica. Natura e origine della mente como meditación sobre la vida.

TRADUCIR LA TRADUCCIÓN. Catalina Cepernic nos presenta la primera traducción al español de "El texto como objeto. Sobre la autonomía recuperada del texto dramático", de Ronald Geerts, docente e investigador vinculado a la Universidad Libre de Bruselas, quien se ha especializado en teatro político en Flandes, Bélgica. El artículo que integra el Dossier fue escrito originalmente para un libro sobre el estatuto del texto en el teatro posdramático en que diverses especialistas de Bélgica analizan, junto 
a Hans-Thies Lehmann, de qué manera se ha ido modificando el texto en relación con los demás elementos en la escena europea contemporánea. Geerts propone una reflexión sobre el texto devenido objeto, materialidad, por caso, en los sobretítulos como recurso muy utilizado en compañías teatrales que llevan a escena sus obras para un público cuya lengua a menudo es otra, como ocurre con Needcompany de Jan Lauwers, o la compañía Discordia. En el texto proyectado, en el escrito en papel, en el sobretítulo como traducción o, justamente, en su ausencia o contradicción, en la presencia explícita del modo de decirse en escena, el texto adquiere una autonomía que permite, dice Geerts, una "emancipación del texto como texto", y los signos teatrales ya no funcionan como "un signo de un signo", sino puramente como un signo de sí mismos. Consideramos que esta traducción de Cepernic es un valioso aporte, por un lado, a la discusión sobre el teatro posdramático, tras el recorrido del concepto acuñado en 1999 por Lehmann y, por otro, al tratarse de un texto escrito originalmente en neerlandés, una lengua muy poco traducida al español, promueve un diálogo más fluido entre las indagaciones europeas y latinoamericanas.

Para finalizar esta presentación, queremos agradecer especialmente a les autores por aceptar ser parte de este Dossier, compartir sus reflexiones y convidarnos, a su vez, a pensar(nos) en este complejo contexto. Gracias también a les artistas e investigadores que cedieron derechos para incluir aquí sus palabras e imágenes. Y gracias a Beatriz Trastoy y todo el Equipo Editorial de telondefondo. Revista de teoría y crítica teatral por la invitación, la confianza y por sostener este espacio de encuentro.

Artículos que componen el presente Dossier

Traducir las experiencias

El idioma del actor y la traducción infinita .................................................... Laurent Berger

Noli me tangere, todavía no soy una imagen Juan Miranda

Traducir las miradas

El texto en escena: operaciones en la puesta de GAS/GAZ

de Tom Lanoye. Catalina Cepernic

Traducción y traslado: aquellas otras palabras en el teatro

de Stoppard Lucas Margarit

Ethica. Natura e origine della mente: una performance que suspende

y triangula luz/cuerpo/mente Adriana Musitano

Traducir la traducción

El texto como objeto. Sobre la autonomía recuperada del texto dramático Ronald Geerts 


\section{Bibliografía}

" Fobbio, L., y van Muylem, M. (2020a). "Dramaturgias del siglo XXI: investigación, creación, traducción y edición”. Recial, revista del CIFFyH, 11 (18). [en línea]. Consultado el 28 de marzo de 2021 en https://revistas.unc.edu.ar/index. $\mathrm{php} / \mathrm{recial} /$ article/view/31278

»Fobbio, L., y van Muylem, M. (202ob). “Teatro, traducción, creación y trampantojo". En Koss, M.N (Comp.) Actas de las IV Jornadas de Investigación del Instituto de Artes del Espectáculo. Buenos Aires: IAE, UBA. [en línea]. Consultado el 10 de marzo de 2021 en http://eventosacademicos.filo.uba.ar/index.php/IIIAE/ IAE2020/paper/view/5283/3142

» Gullar, F. (2015). “Traduzir-se”. En Poemas escolhidos. Rio de Janeiro: Nova Fronteira.

" Musitano, A. y Fobbio, L. (2012). “La puesta en página del monólogo dramático: el martillar y la escritura en voz alta", 485-503. En Brownell, P (Ed. y coord.) Actas IV Jornadas Nacionales de Investigación y Crítica Teatral. Buenos Aires: AINCRIT ediciones. [en línea]. Consultado el 20 de marzo de 2021 en https://drive. google.com/file/d/oB_tISAR5St_dVWx1cmJxZWlsM3ZYbkxHZzhiV2RzZzh6RF9J/view

»Trastoy, B. (2012). “Traducir la Muerte para Pensar el Arte: apuntes sobre la escena posdramática”. Revista brasileira de estudos da presença 2 (1), 231-248. [en línea]. Consultado el 15 de marzo de 2021 en https://www.scielo.br/scielo. php?pid=S2237-26602012000100231\&script=sci_abstract\&tlng=es

»Trastoy, B. (2017). La escena posdramática. Ensayos sobre lo autorreferencial. Buenos Aires: Libretto. 